\title{
Erratum to: Eating two larger meals a day (breakfast and lunch) is more effective than six smaller meals in a reduced-energy regimen for patients with type 2 diabetes: a randomised crossover study
}

\author{
Hana Kahleova • Lenka Belinova • Hana Malinska • Olena Oliyarnyk • \\ Jaroslava Trnovska • Vojtech Skop • Ludmila Kazdova • Monika Dezortova • \\ Milan Hajek • Andrea Tura • Martin Hill • Terezie Pelikanova
}

Published online: 15 October 2014

(C) Springer-Verlag Berlin Heidelberg 2014

\section{Erratum to: Diabetologia}

DOI 10.1007/s00125-014-3253-5

Unfortunately the values for $\triangle \mathrm{HFC}$ in the Abstract and main text and the values on the $y$-axis of the graph in Fig. $2 \mathrm{~b}$ were presented as fractions rather than percentages and were therefore 100 times lower than they should have been. The correct values for $\triangle \mathrm{HFC}$ were $-3.0 \%(95 \% \mathrm{CI}-3.3 \%,-2.7 \%)$ for A6 vs $-4.0 \%(95 \% \mathrm{CI}-4.1 \%,-3.5 \%)$ for B2 ( $p=0.009)$. A corrected version of the graph is shown here.

The online version of the original article can be found at http://dx.doi.org/ 10.1007/s00125-014-3253-5.

H. Kahleova $(\bowtie) \cdot$ L. Belinova $\cdot$ H. Malinska $\cdot$ O. Oliyarnyk

J. Trnovska $\cdot$ V. Skop $\cdot$ L. Kazdova $\cdot$ T. Pelikanova

Diabetes Centre, Institute for Clinical and Experimental Medicine,

Videnska 1958/9, 14021 Prague, Czech Republic

e-mail: hana.kahleova@gmail.com

\section{Belinova}

First Faculty of Medicine, Charles University,

Prague, Czech Republic

M. Dezortova $\cdot$ M. Hajek

Department of Diagnostic and Interventional Radiology, Institute for Clinical and Experimental Medicine, Prague, Czech Republic

\section{A. Tura}

Metabolic Unit, Institute of Biomedical Engineering, National

Research Council, Padua, Italy

M. Hill

Department of Steroid Hormones and Proteohormones, Institute of Endocrinology, Prague, Czech Republic

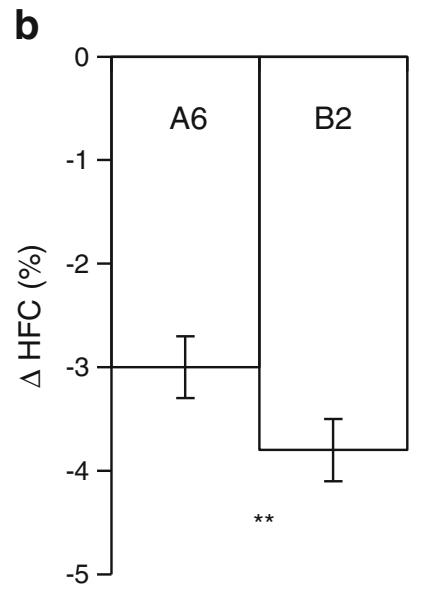

Fig. 2 Changes in anthropometric and laboratory variables. Data are shown as changes from baseline in response to the regimen of six (A6) and two meals (B2) a day. Data are mean $\pm 95 \%$ CI. Significance of the factor treatment (assessed by $2 \times 2$ crossover ANOVA) is indicated by: $* * p<0.01$. (b) $\triangle \mathrm{HFC}, n=48$ 